\title{
Research on the Flow and Exchange of High-Level Talents in Xi'an Under the Background of Port Economic Development
}

\begin{abstract}
Zeng Jiayi
Department of Business, Xi'an Fanyi University, Xi'an, Shaanxi, China

68120801@qq.com

ABSTRACT

With the economic development of Xi'an inland port beginning to take shape, the development of high-level talents as the key foothold to promote the development of related industries, the demand for its high quality is increasing day by day. The overall situation of talents in Xi'an is reflected in that the overall number of talent reserves is relatively sufficient, high-level reserves are relatively scarce, and the mobility and interoperability of talents need to be strengthened. Based on the research of this exhibition, this paper attempts to put forward the strategy of promoting the benign flow and exchange of high-level talents and promoting the economic development of Xi'an port.
\end{abstract}

Keywords: Port Economy, high-level talents, talent flow, talent exchange

\section{口岸经济发展背景下西安高层次人才流动互通问题研 \\ 究}

曾嘉懿

西安翻译学院商学院, 西安, 陕西, 中国

68120801@qq.com

摘要

随着西安内陆港口岸经济发展初具规模, 高层次人才发展作为推动相关联产业发展的关键落脚点, 对其高质量 需求与日俱增。西安市人才目前整体状况体现为人才储备整体数量相对充足, 高层次储备较为贵乏, 人才流动 性、互通性亟待加强。本文基于此展研究, 试图提出促进高层次人才良性流动互通, 推动西安市口岸经济发展 的策略。

关键词: 口岸经济; 高层次人才; 人才流动; 人才互通

\section{1. 研究背景}

口岸经济就是以口岸为核心, 综合利用口岸腹地 资源（人员、商品、资本、技术等），通过汇集、整 合、交换等功能, 以进出口贸易、加工贸易为主体, 依托口岸的软硬件基础设施, 带动相关联的加工、仓 储、贸易、旅游购物、金融服务、配套生活服务等一 系列经济活动, 从而推进现代国际经济合作发展的综 合经济系统。
自 2008 年开始筹建西安国际港务区以来，口岸 经济在推动西安区域经济发展上起到了重要作用。 2013 年国家主席习近平在出访中亚国家期间提出“一 带一路” 倡议, 西安作为国家 “一带一路” 的重要支 点和丝绸之路起点, 在推动枢纽经济、门户经济、流 动经济发展更是得到了长足而快速的发展。

2017 年中国陕西自由贸易试验区正式挂牌, 包 括共有中心, 西安国际港务区, 杨凌示范区三个片区。 其中, 西安国际港务区依托综合保税区、铁路中心站、 公路港三大核心载体，通过西安港、一类口岸及各类 
指定口岸、多式联运监管中心、国家跨境电子商务试 点, 形成了港口移向、无缝多式联运的全国首创的独 特 “国际内陆港模式”。

与此同时, 快速的经济发展出现了巨大的人才需 求。国际化人才作为推动区域发展的根本动力, 是西 安持续推荐 “一带一路” 建设的关键, 这就意味着, 西安的口岸经济能否快速发展, 归根到底还是要依靠 高素质、高层次、高质量的国际化人才。

\section{2. 口岸经济发展背景下的西安市人才发展现 状}

习近平总书记高度重视人才工作, 多次强调人才 是创新的根基, 创新驱动实质上是人才驱动, 谁拥有 一流的创新人才, 谁就拥有了科技创新的优势和主导 权。党的十九大更是把人才资源的重要性提高到了前 所未有的历史新高度, 明确人才是实现民族振兴、赢 得国际竞争主动的战略资源, 并把 “人才强国战 略”作为七大战略的核心支撑。

十九大以来, 各地纷纷颁布多项人才政策, 加入 了 “人才争夺战”，陕西省共颁布人才新政 6 项, 西安市制定了 “ 5 年投入 38 亿元, 引才育才 100 万 名左右” 的人才引进战略目标, 致力于优化城市人口 结构。

\section{1 人才基础储备相对充分}

西安市作为我国西北地区的枢纽门户城市, 在区 域经济布局上, 具有 “承东启西, 东联西引” 的区位 优势, 聚集了西北地区的大量劳动力资源。

同时, 由于自身拥有 76 所高校, 在全国范围内, 高等教育能力也较为突出。据国家统计局西安调查队 2019 年 6 月 21 日发布的《2019 年西安市应届大学毕 业生调查报告》显示, 2019 年陕西省普通高校应届 毕业生达 34.2 万, 且有 $34.1 \%$ 的应届毕业生表示愿 意选择西安。

\section{2 高层次人才吸引力不足}

人才吸引力的分值反映了城市对人才的五种需
求的满足程度。这个分值越高, 对人才需求的满足程 度就越好, 城市吸引人才的能力就强; 这个分值越低, 对人才需求的满足程度就越差, 城市吸引人才的能力 就弱。

根据 BOSS 直聘发布的《2020 一季度人才吸引力 报告》获悉: 2020 年一季度人才吸引力指数前 15 位 城市中, 西安位居第 6 位, 仅次于北京、上海、深圳、 广州、杭州, 可以看出西安的总体吸引人才的能力在 全国城市平均的水平之上。而通过查阅 2016 年研究 生学历以及以上学历的毕业生, $70 \%$ 以上的人才都流 动到东部及沿海的发达地区, 说明西安对于高层次人 才的吸纳力不足。

根据马斯洛需求层次理论, 高层次人才吸引力受 尊重因子和自我实现因子方面影响更为显著。由于西 安在高等教育方面的优势明显, 能够较好满足了人才 的尊重需求。但在自我实现方面, 西安市由于经济发 展水平一般、经济规模不够大, 所以给人才施展才华 的空间是不够宽广的。因而在高层次人才吸引力方面 西安整体表现较弱, 体现为西安的高层次人才密度较 同级城市低（如武汉），总体职称结构呈金字塔型， 与国家要求的两头小，中间大的要求不符。

\section{3 国际化人才水土不服, 劳动争议频发}

作为内陆港口城市, 西安有大量的外资企业以及 外籍务工人员, 这些外企以及外籍务工人员仍旧保持 着原本国家的雇用习惯, 部分习惯与我国的法律法 规, 西安市的地方规定存在着冲突, 这就导致了部分 企业存在着较多的劳动争议, 导致用工不稳定, 流动 较为频繁。

\section{4人才互通模式尚不成熟}

目前, 西安乃至全国一些先进城市的人才雇佣模 式还是以传统雇佣为主, 员工受雇于企业, 企业提供 生产资料并进行管理, 发放薪酬以及相关福利, 并且 承担相应的用工风险。这种雇佣模式成熟且安全, 但 是缺乏灵活性, 无法有效解决劳动力市场对于高层次 人才结构性缺乏的问题。

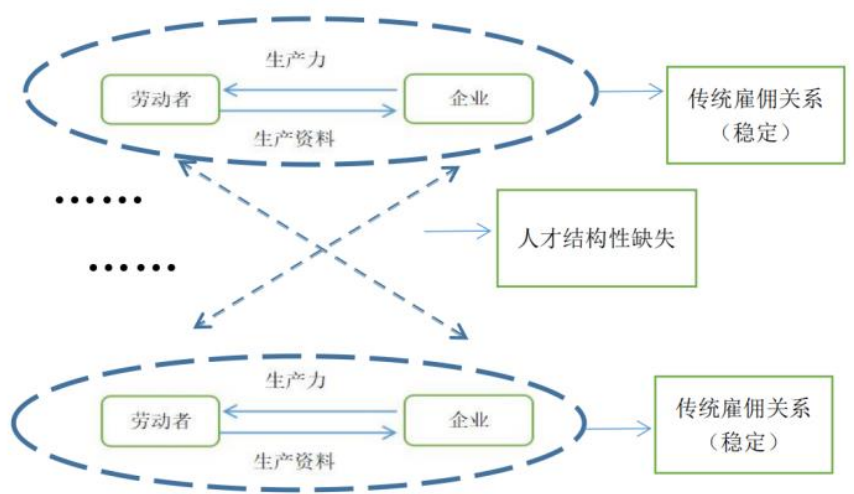

图 1 传统雇佣模式示意图 
面对一个开放性的市场环境, 西安急需打造一个 人才互通平台来进行人力资源共享, 才能更有效的引 进国际人才，从利用西安的 “人口红利” 过渡到利用 全球的 “人才红利”。

\section{3. 改善西安高层次人才流动互通的途径探讨}

\section{1 高校联动, 培养开发符合口岸经济发展需 求的国际化人才}

2016 年, 我国教育部发布了《推进共建 “一带 一路” 教育行动》，对 “一带一路” 教育互通机制的 具体制定和实施进行了全面部署。

“一带一路” 人才互通机制的实施在很大程度 上是为了促进 “一带一路” 沿线各国人才的有序流
动, 通过人才流动盘活人才资源存量、提高人才资源 质量、实现人才资源效用的最大化。

西安政府可依托自身优势高等教育资源, 与国内 外一流知名大学合作, 利用彼此先进的教学理念和教 学力量, 建立国际化人才培养基地, 搭建促进学习、 科研、实践的国际化交流平台, 培养符合口岸经济发 函需求的具有国际化视野的高层次人才。

\section{2 “政企校自” 合作，搭建国际化高层次人 才互通平台}

搭建高层次人才互通平台, 就是在整合口岸城市 构建 “一带一路” 的 “人才共同体” ，充分发挥人才 的作用和价值, 最大限度地激发人才的创新、创造、 创业活力。

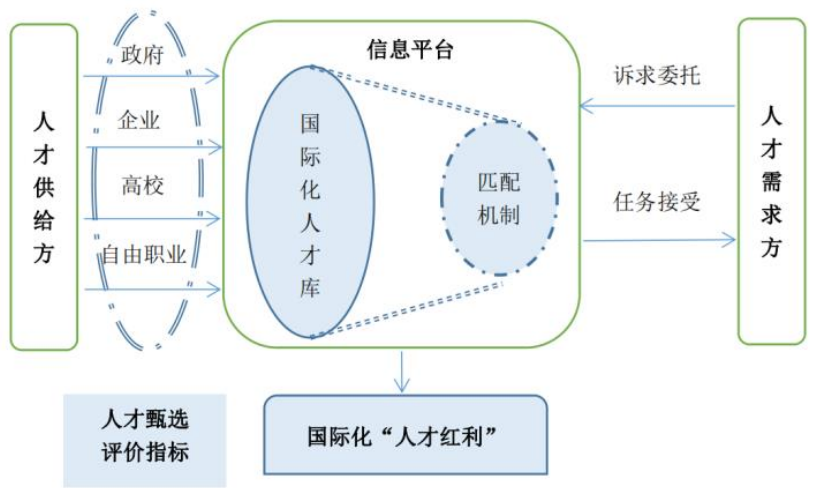

图 2 “政企校自” 国际化人才互通平台示意图

\section{2.1 构建人才甄选评价指标体系}

通过人才互通平台, 整合国内外高层次人才信 息, 来源包括政府、企业、高校以及自由职业等, 在 信息平台内将供给信息与人才需求信息进行匹配, 进 而实现国际化 “人才红利” 的充分利用, 解决结构性 人才缺乏等问题。

在这个过程中, 如何对于高层次人才进行客观有 效甄选, 需要针对于不同行业建立不同的人才甄选评 价指标体系来进行客观评价，可考虑从专业、职称、 学历、从业经历、研究专长等方向来进行构建。

\subsection{2 完善信息匹配机制}

将国际化人才库中的信息和人才需求方具体提 出的诉求委托进行匹配, 是人才互通平台实现的关键 的一环。在匹配的过程中, 要注意以下几个问题: 第 一, 合法性。要注意不同国家、地区的政策差异, 以 及不同职业的行业规范, 以确定满足人才需求方的诉 求委托是一次符合不同国家、地区政策, 遵守相关行 业规范的合理合法的人才互通。第二, 全面性。人才 库的信息应尽可能完整, 真实。才能保证在信息匹配 成功之后快速找到人才供给方, 形成真实有效的互通 关系。

\section{4. 结论}

西安口岸经济的快速发展需要大量高层次人才 的聚集与交流, 与目前西安市人才储备量大, 高层次 人才相对贾乏的现状有所差距。这就要求西安充分挖 掘自身区位优势, 76 家高校探索市内联动, 国内联 动, 乃至国际联动, 共同合作培养具备国际化视野的 高层次人才的途径; 同时，实现 “政企校自” 四者的 有效互通，构建人才甄选评价指标体系，进行人才信 息的有效匹配，搭建 “政企校自” 国际化高层次人才 互通平台。

\section{项目基金}

本文为西安翻译学院线上线下混合式课程建设 项目《管理学实务》(ZK2020) 的阶段性成果之一。

\section{REFERENCES}

[1] Ji,J.,Song,F.,Li,Wc..(2019)Analysis on the Construction of High-level Talent Exchange platform for Beijing-Tianjin-Hebei Cultural Industry. Cultural industry.12:37-39.

[2] Zhang,L..(2017)Talent Exchange in the 
Construction of "Belt and Road Initiative": mode, implementation path and existing problems. Technical economy.36:38-44.

[3] Ma,Z..(2020)Research on the coordinated Economic Development of Xi'an Inland Port under the background of Free Trade Zone Construction. China Economic and Trade Guide. 37:52-53.
[4] Lin,X.,Su,Wl..(2019)Research on the flow and training Mechanism of internationalized talents under the background of "Belt and Road Initiative". Modern management science. 38:84-86. 